\title{
Role of cholera toxin in Vibrio cholerae infection in humans - A Review
}

\author{
Partha Pal \\ Department of Zoology, Scottish Church College, 1 \& 3 Urquhart Square, Kolkata - 700006, India \\ Phone: 91-33-2350-3862 \\ E-mail address: parthapal_iicb@yahoo.co.in
}

\begin{abstract}
Vibrio cholerae, the causative agent of Asiatic cholera, is a gram-negative motile bacterial species acquired via oral ingestion of contaminated food or water sources. Cholera has spread from the Indian subcontinent where it is endemic to involve nearly the whole world seven times during the past 185 years. $V$. cholerae serogroup O1, biotype El Tor, has moved from Asia to cause pandemic disease in Africa and South America during the past 35 years. A new serogroup, O139, appeared in south Asia in 1992, has become endemic there, and threatens to start the next pandemic. The facultative human pathogen $V$. cholerae represents a paradigm that evolved from environmental nonpathogenic strains by acquisition of virulence genes. The major virulence factors of $V$. cholerae, cholera toxin (CTX) encoded by the $\operatorname{ctx} A B$ genes residing in the genome of filamentous lysogenic bacteriophage $(\mathrm{CTX} \phi)$ and toxin coregulated pilus (TCP) encoded by vibrio pathogenicity island (VPI). CTX, a potent stimulator of adenylate cyclase, causes the intestine to secrete watery fluid rich in sodium, bicarbonate, and potassium, in volumes far exceeding the intestinal absorptive capacity, by ADP-ribosylation of the alpha subunit of the GTP-binding protein. Thus intestinal infection with $V$. cholerae results in the loss of large volumes of watery stool, leading to severe and rapidly progressing dehydration and shock. Without adequate and appropriate rehydration therapy, severe cholera kills about half of affected individuals. Today, cholera still remains a burden mainly for underdeveloped countries, which cannot afford to establish or to maintain necessary hygienic and medical facilities. During the last three decades, intensive research has been undertaken to unravel the virulence properties and to study the epidemiology of this significant human pathogen. This review provides an overview of the role of CTX in the occurrence of this disease in humans.
\end{abstract}

Keywords: Vibrio cholerae; bacteriophage; TCP; CTX phage; Cholera infection; Humans

\section{INTRODUCTION}

The genus Vibrio belongs to the family Vibrionaeceae and consists of 44 recognized species of which 12 species are involved in human infections (Brenner et al., 2005). $V$. cholerae $\mathrm{O} 1$ is the causative agent of pandemic cholera. $V$. cholerae $\mathrm{O} 139$ strain (isolated from Bengal) was reported to be another causative agent of cholera (Ramamurthy et al., 1993). The epidemic causing strains of $V$. cholerae (O1 or O139 serogroups) produce cholera toxin (CTX) which is the major contributing factor for profuse diarrohea (cholera gravis) with rice water stools, dehydration and electrolyte imbalance. Cholera Toxin (CTX) encoded by $\operatorname{ctx} A B$ is responsible for the severe diarroheal symptoms elicited by $V$. cholera (Kaper et al., 1995). CTX is a potent A-B type exotoxin composed of $5 \mathrm{~B}$ subunits $(\operatorname{ctx} B)$ which binds holotoxin to the cell receptor and one A subunit $(\operatorname{ctx} A)$ which provides intracellular activity. $V$. cholerae O1 strains and O139 strains produce CTX (Nair and Takeda, 1993) but in $V$. 
cholera non-O1 serogroups the expression of CTX is rare (Said et al., 1994). However, there are certain environmental strains that possess the ctx gene (Nair et al., 1988; Rivera et al., 2001). The toxigenic O139 serogroups have evolved from recombination with toxigenic $\mathrm{O} 1$ strains (Faruque et al., 2000a) and it has been hypothesized that $V$. cholerae non-O1/nonO139 strains can acquire genes for toxin production by transduction and might be the source of new epidemics (Rao and Surendran 2003). V. cholera classical (CL) biotype was isolated, along with biotype El Tor (ET) and altered ET carrying the cholera toxin (CTX) gene of CL biotype, during the 1991 cholera epidemic in Mexico, subsequently becoming endemic until 1997 (Nair et al., 2006). Microbiological, molecular, and phylogenetic analyses of $V$. cholera isolated from both clinical and environmental samples during 1998-2008 confirm important genetic events, namely predominance of ET over CL and altered ET in Mexico (Nair et al., 2006). Although altered ET is predominantly associated with cholera globally, progression of CTX positive $V$. cholerae ET with truncated CTX prophage to the predominant pathogen causing endemic cholera in Mexico may prove to be yet another key historical point in the global epidemiology of cholera (Alama et al., 2014).

Miller and Mekalonas cloned the relatively weak promoter for cholera toxin $(\operatorname{ctx} A B)$ into Escherechia coli as an operon fusion to lacZ and subsequently identified a regulatory gene toxR whose expression in this $E$. coli background resulted in elevated ctx-lacZ expression (Miller and Mekalonas, 1984). This experimental observation gave an insight into the regulation of $c t x$ as well as several other factors in the pathogenesis of cholera. Cholera toxin encoded by $\operatorname{ctx} A B$ is responsible for the severe diarrheal symptoms elicited (Kaper et al., 1995), and toxin coregulated pilus (TCP) encoded by tcp $A$ is responsible for efficient colonization of the human intestinal tract by the bacterium (Tacket et al., 1998; Taylor et al., 1987). In addition, the $\mathrm{O}$ antigen is the bacterium's major protective antigen, and therefore, changes in the $\mathrm{O}$ antigen of a preexisting epidemic strain may result in a new pathogen capable of causing disease in populations immune to the original epidemic strain (Albert et al., 1993a; Ramamurthy et al., 1993). The $c t x A B$ genes are carried in the genome of a filamentous, single-stranded DNA phage designated CTX $\phi$ (Waldor and Mekalonas 1996), and their dissemination to nonpathogenic strains may, therefore, occur via phage-mediated horizontal gene transfer.

The TCP structural gene, tcpA, has been mapped (Karaolis et al., 1998) to a gene cluster designated the vibrio pathogenicity island (VPI), and the VPI has recently been proposed (Karaolis et al., 1999) to also be a filamentous phage, VPI $\phi$. TCP has clearly been demonstrated (Rhine and Taylor 1994; Taylor et al., 1987; Waldor and Mekalonas 1996) to be the receptor for СТX $\phi$ and to be the bacterium's colonization factor ( $\mathrm{Li}$ et al., 2003). The present review is based on the role of CTX in the virulence attribute of $V$. cholerae isolates.

\section{ISOLATION OF $V$. cholerae ISOLATES}

Stool samples should be collected early in the illness, preferably before the initiation of antibiotic therapy. Samples can be collected from sterile bedpans or containers, but during epidemic infections specimen collections from bedpans may yield false-positives due to contamination by previous use or false-negatives due to the presence of residual disinfectants. Reasonable recovery rates are also possible with rectal swabs. When processing of specimens is delayed, the stool sample or swabs can be placed in Cary-Blair transport medium; viability of $V$. cholerae for up to 4 weeks in this medium has been reported (Kelly et al., 1991). Two broth media used for enrichment of $V$. cholerae can also be used for transport. Alkaline peptone water and tellurite-taurocholate-peptone broth have both been successfully used for transport of specimens, although prolonged holding in alkaline peptone water at ambient 
temperatures may allow Pseudomonas spp. and non-O1 $V$. cholerae to overgrow $V$. cholerae O1 (Pal, 1992). Strips of filter paper soaked in liquid stool and sealed in airtight plastic bags have also been used to retain viable $V$. cholerae for up to 5 weeks (Kelly et al., 1991). Vibrios are more susceptible to refrigeration than enteric bacilli, and so specimens in transport media should be shipped to the laboratory without refrigeration.

\section{1. Culture media used for $V$. cholerae isolation}

In situations when the concentration of $V$. cholerae is high (107 to 108 per ml of liquid feces) then enrichment is not required. Alkaline peptone water is the most commonly used as enrichment broth (Pal, 1992) and the $\mathrm{pH}$ of this medium can range from 8.4 up to 9.2, thus taking advantage of the ability of $V$. cholerae to multiply at alkaline $\mathrm{pH}$. Enrichment lasts for only 6 to $8 \mathrm{~h}$, as incubation in alkaline peptone water for longer than $8 \mathrm{~h}$ may result in overgrowth of other organisms. Less commonly used enrichment media include alkaline peptone water with tellurite (Pal, 1992), Monsur's tellurite-taurocholate broth (Monsur, 1963), and sodium-gelatin phosphate broth (Rennels et al., 1980). Examination of food and water samples for $V$. cholerae nearly always utilizes one if not two enrichment steps. When a second enrichment is used to avoid overgrowth of other organisms in the initial broth, alkaline peptone is used first for no more than $8 \mathrm{~h}$ followed by enrichment in a more selective broth such as Monsur's tellurite-taurocholate medium (Sakazaki, 1992). The commonly used plating medium for $V$. cholerae is thiosulfate-citrate bile salts-sucrose (TCBS) agar, which is available commercially.

The sucrose-fermenting $V$. cholerae isolates are readily detected on this medium as large, yellow, smooth colonies. Additional selective media (Pal, 1992; Dizon, 1974) have been developed for isolation of $V$. cholerae and include Monsur's telluritetaurocholate gelatin agar (Monsur, 1963), vibrio agar (Tamura et al., 1971), and polymyxin-mannose-tellurite agar (Shimada et al., 1990), but these are not commercially available. Most selective media commonly used for isolation of members of the family Enterobacteriaceae are not suitable for isolation of $V$. cholerae, but some success has been reported with MacConkey agar (Kelly et al., 1991). Nonselective media such as blood agar plates are excellent for the growth of $V$. cholerae, but with such media overgrowth by unwanted species is potentially a problem.

\section{EMERGENCE OF Vibrio cholerae STRAINS}

The Italian scientist Pacini, in 1854 first described the causative agent for cholera, who found a large number of comma-shaped bacteria in the intestinal contents of cholera infected patients and coined them Vibrio cholera (Pollitzer, 1959).

$V$. cholerae is a well-defined species on the basis of biochemical tests and DNA homology studies (Baumann et al., 1984). However, this species is not homogeneous with regard to pathogenic potential. Specifically, important distinctions within the species are made on the basis of production of cholera enterotoxin (CTX), serogroup, and potential for epidemic spread. Until recently, the public health distinction was simple; that is, $V$. cholerae strains of the O1 serogroup which produced CTX were associated with epidemic cholera, and all other members of the species either were nonpathogenic or were only occasional pathogens. However, with the epidemic of cholera due to strains of the O139 serogroup, such previous distinctions are no longer valid. There are two serogroups, O1 and O139, that have been associated with epidemic disease, but there are also strains of these serogroups which do not produce CTX, do not produce cholera, and are not involved in epidemics. Conversely, there are occasional strains of serogroups other than $\mathrm{O} 1$ or $\mathrm{O} 139$ that are clearly pathogenic, either by the production of CTX or other virulence factors. However, none of these other 
serogroups have caused large epidemics or extensive pandemics. Therefore, in assessing the public health significance of an isolate of $V$. cholerae, there are two critical properties to be determined beyond the biochemical identification of the species $V$. cholerae. The first of these properties is production of CTX, which is the toxin responsible for severe, cholera-like disease in epidemic and sporadic forms. The second property is possession of the $\mathrm{O} 1$ or $\mathrm{O} 139$ antigen, which since the actual determinant of epidemic or pandemic potential is not known, is at least a marker of such potential (Kaper et al., 1995).

$V$. cholerae $\mathrm{O} 1$ serogroup that produces CTX has long been responsible with epidemic and pandemic cholera. Some isolates of $V$. cholerae $\mathrm{O} 1$ do not produce CTX and also do not possess the $c t x$ genes encoding CTX (Kaper et al., 1981). Environmental strains are usually CTX negative and are considered to be nonpathogenic (Levine et al., 1982). However, CTXnegative $V$. cholerae $\mathrm{O} 1$ strains has been isolated from occasional cases of diarrhea (Morris et al., 1984) or extraintestinal infections. This serogroup can be further subdivided into serotypes of the $\mathrm{O} 1$ serogroup called Ogawa and Inaba, a third serotype which is rarely isolated is Hikojima. $V$. cholerae $\mathrm{O} 1$ can also be divided into two biotypes, classical and $\mathrm{El}$ Tor. All combinations can be isolated i.e., classical strains which are Inaba or Ogawa and El Tor strains which are Inaba or Ogawa.

Until the emergence of the $\mathrm{O} 139$ serogroup, all isolates that were identified as $V$. cholerae on the basis of biochemical tests but that were negative for the $\mathrm{O} 1$ serogroup were referred to as "non-O1 $V$. cholerae." In earlier years, the non-O1 $V$. cholerae was referred to as non-cholera vibrios or nonagglutinable vibrios. In view of the emergence of epidemic O139 disease, O2-O138 strains can be referred to as nonepidemic $V$. cholerae isolates. These non-O1/non-O139 strains have been divided into serogroups $\mathrm{O} 2$ through $\mathrm{O} 138$ on the basis of the lipopolysaccharide (LPS) somatic antigen. The great majority of these strains does not produce CTX and are not associated with epidemic diarrhea (Morris, 1990). These strains are occasionally isolated from cases of diarrhea (usually associated with consumption of shellfish) and have been isolated from a variety of extraintestinal infections, including wounds, ear, sputum, urine, and cerebrospinal fluid (Hughes et al., 1978; Morris and Black 1985; Morris, 1990; Morris et al., 1981). They are regularly found in estuarine environments, and infections due to these strains are commonly of environmental origin (Morris, 1990).

The difference between $V$. cholerae $\mathrm{O} 1$ and $V$. cholerae non $\mathrm{O} 1$ was rendered obsolete in early 1993 when the first reports of a new epidemic of severe, cholera-like disease emerging from eastern India and Bangladesh appeared (Albert et al., 1993b). At first, the organism responsible for this outbreak was referred to as non-O1 $V$. cholerae because it did not agglutinate in $\mathrm{O} 1$ antisera. However, further investigations revealed that this organism did not belong to the $\mathrm{O}$ serogroups previously described for $V$. cholerae but to a new serogroup, which was given the designation $\mathrm{O} 139$ and a synonym "Bengal,' in recognition of the origin of this strain (Shimada et al., 1993). In general, this organism appears to be a hybrid of the $\mathrm{O} 1$ strains and the non-O1 strains. In important virulence characteristics, specifically, cholera enterotoxin and toxin-coregulated pilus (TCP), V. cholerae $\mathrm{O} 139$ is indistinguishable from typical El Tor $V$. cholerae O1 strains (Hall et al., 1993; Rhine and Taylor 1994). However, this organism does not produce the O1 LPS and lacks at least some of the genetic material necessary for production of the O1 antigen (Manning et al., 1994). Furthermore, like many strains of non-O1 $V$. cholerae and unlike $V$. cholerae $\mathrm{O} 1$, this organism produces a polysaccharide capsule (Kaper et al., 1995).

\section{CHOLERA TOXIN (CTX)}

$V$. cholerae produces a variety of extracellular products that have dangerous effects on eukaryotic cells. The enormous diarrhea causing dehydration which is the characteristic of 
cholera is induced by cholera enterotoxin, also referred to as CTX or choleragen. However, $V$. cholerae strains carrying deleted $c t x$ genes can still cause mild to moderate diarrhea in many individuals and this has prompted a search for additional toxins produced by $V$. cholerae (Kaper et al., 1995).

The existence of a toxin responsible for the symptoms of cholera was first advanced by Robert Koch, who in 1884 proposed that the agent responsible for cholera produces "a special poison" which acted on the intestinal epithelium and that the symptoms of cholera could be "regarded essentially as a poisoning'" (Koch, 1884). The existence of this hypothesized toxin was demonstrated in 1959 by two independent groups of researchers working in India. S. N. De (De, 1959) and Dutta et al. (Dutta et al., 1959) demonstrated that an outpouring of fluid resulted when culture filtrates or lysates of $V$. cholerae were introduced into the rabbit intestinal tract. Purification of the toxin 10 years later by Finkelstein and LoSpalluto (Finkelstein and LoSpalluto 1969) encouraged other investigators to decipher the fundamental properties of the toxin such as structure, receptor binding, and mode of action. These findings have been extensively reviewed by later researchers (Finkelstein, 1992; van Heyningen and Seal 1983).

\section{1. CTX structure}

The structure of CTX is typical of the A-B subunit group of toxins in which each of the subunits has a specific function. The B subunit serves to bind the holotoxin to the eukaryotic cell receptor, and the A subunit possesses a specific enzymatic function that acts intracellularly. CTX consists of five identical B subunits and a single A subunit, and neither of the subunits individually has significant secretogenic activity in animal or intact cell systems. The mature B subunit contains 103 amino acids with a subunit weight of $11.6 \mathrm{kDa}$. The mature A subunit has a mass of $27.2 \mathrm{kDa}$ and is proteolytically cleaved to yield two polypeptide chains, a 195 -residue A1 peptide of $21.8 \mathrm{kDa}$ and a 45 -residue A2 peptide of 5.4 $\mathrm{kDa}$. After proteolytic cleavage, the A1 and A2 peptides are still linked by a disulfide bond before internalization (Gill and Rappaport 1979). Formation of intrachain disulfide bonds within the A and B subunits is catalyzed by disulfide isomerase (Yu et al., 1992). The same enzyme is essential for assembly of the TCP of $V$. cholerae, which contains an intrachain disulfide bond (Peek and Taylor 1992). The other steps of CTX assembly and secretion into the extracellular environment are not as well characterized as the disulfide bond formation (Hirst, 1991). The crystal structures for CTX and the highly similar LT of ETEC have been determined (Sixma et al., 1991). The B subunits form a pentamer via interactions between $b$ sheets of adjacent monomers. A pore of 11 to $15 \AA(1.5$ to $1.5 \mathrm{~nm})$ is formed in the center of the pentamer; the $\mathrm{C}$-terminal end of the $\mathrm{A} 2$ peptide sits in this pore and binds to the $\mathrm{B}$ pentamer by numerous interactions between polar and charged residues. The N-terminal half of the A2 is a long a-helix which extends outside the B pentamer and interacts with the A1 peptide. The A1 peptide has structural homology with the catalytic region of Pseudomonas aeruginosa exotoxin A and diphtheria toxin (Sixma et al., 1991).

\section{2. CTX receptor binding}

The receptor for CTX is the ganglioside GM1 [Galb133GalNAcb1(NeuAca233)3Glcceramide, where Gal refers to galactose, GalNAc is $N$-acetylgalactosamine, Glc is glucose, and NeuAc is $N$ acetylneuraminic acid (sialic acid)] (King and van Heyningen 1973; Spangler, 1992). The binding between CTX and the receptor occurs via the B subunit; addition of purified B subunit (also known as choleragenoid) or GM1 to rabbit ileal loops before addition of CTX inhibits fluid secretion (King and van Heyningen 1973; Pierce, 1973). Antibodies directed against B, the immunodominant subunit, are much more efficient 
at neutralizing toxin activity than are antibodies directed against the A subunit (Peterson et al., 1979; Svennerholm, 1980). Interaction of CTX to epithelial cells is enhanced by a neuraminidase (NANase) produced by $V$. cholerae. This enzyme, with a molecular mass of $83 \mathrm{kDa}$ (Galen et al., 1992), enhances the effect of CTX by catalyzing the conversion of higher-order gangliosides to GM1 (Holmgren et al., 1975). Experiments with purified NANase and 125I-labeled CTX showed that isolated rabbit small-intestine brush borders or cultured mouse neuroblastoma cells exposed to NANase bound 2 to 7 times more CTX than did untreated cells (Griffiths et al., 1986; Miller-Podraza et al., 1982). In ligated canine ileal loops injected with CTX, secretion increased fourfold in loops pretreated with NANase compared with untreated control loops (Staerk et al., 1974). Using isogenic $V$. cholerae strains specifically mutagenized in the gene encoding NANase $(n a n H)$ and flow cytometry, Galen et al., (Galen et al., 1992) showed that fluorescence due to binding of fluoresceinconjugated CTX to mouse fibroblasts exposed to NANase-positive culture filtrates increased five- to eightfold relative to binding to cells exposed to NANase-negative filtrates.

\section{3. Enzymatic activity associated with CTX}

The intracellular target enzyme of CTX is adenylate cyclase in eukaryotic cells. This enzyme transforms ATP to cyclic AMP (cAMP). G-protein regulates the activity of adenylate cyclase which links many cell surface receptors to effector proteins at the plasma membrane. The specific $G$ protein involved is the $G_{s}$ protein, activation of which leads to increased adenylate cyclase activity. CTX catalyzes the transfer of the ADP-ribose moiety of NAD to a specific arginine residue in the $\mathrm{G}_{\mathrm{s} \alpha}$ protein, resulting in the activation of adenylate cyclase and subsequent increases in intracellular levels of cAMP. cAMP activates a cAMP-dependent protein kinase, leading to protein phosphorylation, alteration of ion transport, and leading to diarrhea. After CTX binds to epithelial cells, there is a lag of 15 to $60 \mathrm{~min}$ before adenylate cyclase is activated (Gill and King 1975). The lag time is necessary to allow the A1 peptide to translocate through the membrane and to come into contact with the $G$ proteins. The adenylate cyclase is located on the basolateral membrane of polarized intestinal epithelial cells, and a variety of mechanisms have been proposed to explain how CTX bound to the brush border (apical) membrane reaches the basolateral adenylate cyclase. The most accepted explanation is that whole CTX enters the cells by endocytosis and the low $\mathrm{pH}$ of the endosomal compartment facilitates the translocation of the A subunit across the endosomal membrane. The endosome then penetrates through the cell with the Al peptide still associated with the endosomal membrane. Ultimately, the A1 peptide ADPribosylates $\mathrm{G}_{\mathrm{s} \alpha}$ is located in the basolateral membrane. Recently it has been reported that the action of CTX is completely inhibited by a fungal metabolite, Brefeldin A, which interferes with vesicular transport in endosomal and transcytotic pathways of many eukaryotic cells (Donta et al., 1993; Lencer et al., 1993; Lencer et al., 1992; Nambiar et al., 1993). These results show that an intact Golgi region is required for intracellular movement of CTX. The A1 peptide catalyzes the transfer of ADP-ribose from NAD to an arginine residue on $G_{s \alpha}$. ADPribosylation of the a subunit by the A1 peptide of CTX inhibits the hydrolysis of GTP to GDP, thus leaving adenylate cyclase constitutively activated, probably for the life of the cell (Cassel and Selinger 1977; Kahn and Gilman 1984). The ADP-ribosylation activity of A1 is stimulated in vitro by a family of proteins termed ADP-ribosylation factors (ARFs) (Moss and Vaughan 1991).

\section{4. Cellular effect in response to CTX}

The increased intracellular cAMP concentrations resulting from the activation of adenylate cyclase by CTX lead to increased $\mathrm{Cl}^{-}$secretion by intestinal crypt cells and 
decreased NaCl-coupled absorption by villus cells (Field, 1981). The net movement of electrolytes into the lumen results in a transepithelial osmotic gradient which causes water flow into the lumen. The massive volume of water overwhelms the absorptive capacity of the intestine, resulting in diarrhea. Pioneering work in this area by Field (Field, 1971; Field et al., 1969) and subsequent investigators (Finkelstein, 1992) demonstrated that CTX could concomitantly increase cAMP formation and ion transport in isolated intestinal epithelium mounted in Ussing chambers. One crucial step resulting from increased cAMP levels is activation of protein kinase A, which subsequently phosphorylates numerous substrates in the cell (Chang and Rao 1991). Although it is clear that chloride channels can be regulated by cAMP-dependent protein kinases, the actual ion channel or channels affected by the CTX are not known with certainty. There are multiple types of $\mathrm{Cl}_{2}$ channels in apical membranes with different modes of activation and subcellular distribution (de Jonge, 1991). It is also not certain if protein kinase A directly phosphorylates the ion channel or if it phosphorylates an intermediate protein which then phosphorylates other proteins in a cascade.

\section{THE ORIGIN OF ctx GENE IN $V$. cholerae ISOLATES}

The structural genes for the CTX element reside on a filamentous phage $\operatorname{ctx} \Phi$ (Waldor and Mekalanos 1996). СТX $\Phi$ is found in all epidemics $V$. cholerae isolates but is rarely recovered from the non-O1/non-O139 $V$. cholerae environmental isolates. A DNA probe study showed that a small percentage of environmental strains of $V$. cholerae non-O1 have the $c t x$ gene (Nair et al., 1988). Virulence genes including $c t x A B$ were found among environmental strains from Calcutta, India (Chakraborty et al., 2000). Occurrence of $\operatorname{ctx} A$ was found among $10 \%$ on non-O1/non- O139 environmental isolates from Brazil (Rivera et al., 2001). Clinical toxigenic $V$. cholerae isolates are closely related to non-toxigenic environmental strains (Jiang et al., 2000) and ctx genes are highly mobile among environmental isolates. The spread of ctx genes in the environment can be facilitated by the exposure of СТХФ positive strains to sunlight (Faruque et al., 2000b). Genetic and phenotypic evidence strongly suggests that the $\mathrm{O} 139$ strain arose from a $V$. cholerae $\mathrm{O} 1$ strain by horizontal gene transfer (Bik et al., 1995; Comstock et al., 1996; Waldor and Mekalanos 1994; Faruque et al. 2000a). Similarly, V. cholerae non-O1/ non-O139 strains can also acquire toxigenic genes for toxin production by transduction and therefore might be the source of new epidemics. Hypothesis of the existence of a TCP-independent mechanism for infection by СТХФ was proposed by (Jiang et al., 2003). The choleratoxigenic $V$. cholerae (non-O1/non-O139) isolated from shrimp aquaculture system showed greater genetic similarity with $c t x$ negative $V$. cholerae than amongst $c t x$ positive $V$. cholerae (Rao and Surendran 2010). Keeping these in view, the screening of environmental and food samples for the presence of ctx positive $V$. cholerae, especially within the non-O1/ non-O139 serogroup, is of paramount importance. The $V$. cholerae duplex-PCR method developed in this study would be a useful tool to screen for ctx positive $V$. cholerae. Even though the existence of ctx carrying non-O1/non-0139 $V$. cholerae isolates was very low in shrimp culture system, the ecological significance of ctx genes among these $V$. cholerae non-O1 and non- O139 isolates in the shrimp aquaculture environment needs to be further investigated. Study on the expression of $c t x$ gene by the $c t x$ positive non- O1/non-O139 V. cholerae was not performed. Additional study on the expression of $c t x$ genes would unravel the ecological significance of $c t x$ genes in non-O1/non-O139 V. cholerae (Rao and Surendran 2013).

\section{DISCUSSION AND CONCLUSION}


In many pathogenic bacteria, genes that encode virulence factors are located in the genomes of prophages. Thus bacteriophages are important vectors for disseminating virulence genes within bacterial genomes. The filamentous phage $\operatorname{CTX} \varphi$, that carries genes encoding cholera toxin (CTX), is found in V. cholerae (Waldor and Friedman 2005). Recent finding reported that in El Tor biotype strains of toxigenic $V$. cholerae, the CTX $\varphi$ prophage often resides adjacent to a chromosomally integrated satellite phage genome. This result provides new insights on the mechanism of emergence of highly pathogenic variant isolates of $V$. cholerae (Kamruzzaman et al., 2014). Despite more than a century of study, cholera is not a disease of merely historical interest and it still remains a challenging disease about which microbiologists and physicians should be knowledgeable. The role played by CTX in the development of cholera infection in humans is still a budding problem in the control of the disease.

In this present review it is concluded that the CTX protein encoded by the CTX $\varphi$ in $V$. cholerae isolates is a major threat in the attainment of the symptoms of the disease. Although extensive researches are going on through out the world in the control of the disease more nucleotide sequence based data are required since the current trends of horizontal gene transfer among the $V$. cholerae isolates have given rise to emergence of new pathogenic strains. This review will help researchers to know the current status of $V$. cholerae strains throughout the world and also provide informations regarding the role played by CTX in cholera infection in humans.

\section{References}

[1] Alama M. etal., Proc Natl Acad Sci USA 111 (2014) 9917-9922.

[2] Albert M.J. etal., Lancet 342 (1993a) 387-390

[3] Albert M.J., Siddique A.K., Islam M.S., Faruque A.S.G., Ansaruzzaman M., Faruque S.M., Sack R.B., Lancet 341 (1993b) 704.

[4] Baumann P., Furniss A.L., Lee J.V., Bergey’s Man Sys Bact 1 (1984) 518-538.

[5] Bik E.M., Bunschoten A.E., Gouw R.D., Mooi F.R., EMBO J 14(1995) 209-216.

[6] Brenner D.J., Krieg N.R., Staley J.T., Bergey’s Man Systematic Bacteriology 2 (2005) 491-546.

[7] Cassel D., Selinger Z., Proc Natl Acad Sci USA 74 (1977) 3307-3311.

[8] Chakraborty S. et al., Appl Environ Microbiol 66 (2000) 4022-4028.

[9] Chang E.B., Rao M.C., Diarrheal diseases Elsevier New York (1991) 49-72.

[10] Comstock L.E., Johnson J.A., Michalski J.M., Morris J.G. Jr., Kaper J.B., Mol Microbiol 19 (1996) 815-826.

[11] de Jonge H., Molecular pathogenesis of gastrointestinal infections Plenum Press New York (1991) 107-114.

[12] De S.N., Nature (London) 183 (1959) 1533-1534.

[13] Dizon J.J., W.B. Saunders Co. Philadelphia (1974) 367-379.

[14] Donta S.T., Beristain S., Tomicic T.K., Infect Immun 61 (1993) 3282-3286.

[15] Dutta N.K., Panse M.W., Kulkarni D.R., J Bacteriol 78 (1959) 594-595. 
[16] Faruque S.M., Saha Asadulghani M.N., Sack D.A., Sack R.B., Takeda Y., Nair G.B., J Infect Dis 182 (2000a) 1161-1168.

[17] Faruque S.M., Saha Asadulghani M.N., Rahman M.M., Waldor M.K., Sack D.A., Infect Immun 68 (2000b) 4795-4801.

[18] Field M., Physiology of the gastrointestinal tract Raven Press New York (1981) 963-982.

[19] Field M., N Engl J Med 284 (1971) 1137-1144.

[20] Field M., Fromm D., Wallace C.K., Greenough W.B.III., J Clin Invest 48 (1969) 24.

[21] Finkelstein R.A., Plenum Medical Book Co. New York 3 (1992) 155-187.

[22] Finkelstein R.A., LoSpalluto J.J., J Exp Med 130 (1969) 185-202.

[23] Galen J.E., Ketley J.M., Fasano A., Richardson S.H., Wasserman S.S., J Kaper. B., Infect Immun 60 (1992) 406-415.

[24] Gill D.M., King C.A., J Biol Chem 250 (1975) 6424-6432.

[25] Gill D.M., Rappaport R.S., J Infect Dis 139 (1979) 674-680.

[26] Griffiths S.L., Finkelstein R.A., Critchley D.R., Biochem J 238 (1986) 313-322.

[27] Hall R.H., Khambaty F.M., Kothary M., Keasler S.P., Lancet 342 (1993) 430.

[28] Hirst T.R., Sourcebook of bacterial protein toxins Academic Press London (1991) 75-100.

[29] Holmgren J., Lonnroth I., Mansson J., Svennerholm L., Proc Natl Acad Sci USA 72 (1975) 2520-2524.

[30] Hughes J.M., Hollis D.G., Gangarosa E.J., Weaver R.E., Ann Intern Med 88 (1978) 602-606.

[31] Jiang S., Chu W., Fu W., Appl Environ Microbiol 69 (2003) 7541-7544.

[32] Jiang S.C., Matte M., Matte G., Huq A., Colwell R.R., Appl Environ Microbiol 66 (2000) 148-153.

[33] Kahn R.A., Gilman A.G., J Biol Chem 259 (1984) 6235-6240.

[34] Kamruzzaman M., Robins W.P., Bari S.M., Nahar S., Mekalanos J.J., Faruque S.M., Infect Immun Epub (2014).

[35] Kaper J.B., Moseley S.L., Falkow S., Infect Immun 32 (1981) 661-667.

[36] Kaper J.B., Morris J.G. Jr, Levine M.M., Clin Microbiol Rev 8 (1995) 48-86.

[37] Karaolis D.K., Johnson J.A., Bailey C.C., Boedeker E.C., Kaper J.B., Reeves P.R., Proc Natl Acad Sci USA 95 (1998) 3134-3139.

[38] Karaolis D.K., Somara S., Maneval Jr D.R., Johnson J.A., Kaper J.B., Nature 399 (1999) 375-379.

[39] Kelly M.T., Hickman-Brenner F.W., Farmer III J.J., Man Clin Microbiol 5 (1991) 384-395.

[40] King C.A., van Heyningen W.E., J Infect Dis 127 (1973) 639-647.

[41] Koch R., Br Med J (1884) 403-407.

[42] Lencer W.I., de Almeida J.B., Moe S., Stow J.L., Ausiello D.A., Madara J.L., J Clin 
Invest 92 (1993) 2941-2951.

[43] Lencer W.I., Delp C., Neutra M.R., Madara J.L., J Cell Biol 117 (1992) 1197-1209.

[44] Levine M.M., Black R.E., Clements M.L., Cisneros L., Saah A., D. Nalin R., Gill D.M., Craig J.P., Young C.R., Ristaino P., J Infect Dis 145 (1982) 296-299.

[45] Li M., Kotetishvili M., Chen Y., Sozhamannan S., Appl Environ Microbiol 69 (2003) $1728-1738$.

[46] Manning P.A., Stroeher U.H., Morona R., ASM Press Washington D.C. (1994) 77-94. Monsur K.A., Bull W.H.O 28 (1963) 387-389.

[47] Miller-Podraza H., Bradley R.M., Fishman P.H., Biochemistry 21 (1982) 3260-3265.

[48] Miller V.L., Mekalanos J.J., Proc Natl Acad Sci USA 81 (11) (1984) 3471-3475.

[49] Morris J.G.Jr., Epidemiol Rev 12 (1990) 179-191.

[50] Morris J.G., Black Jr.R.E., N Engl J Med 312 (1985) 343-350.

[51] Morris J.G., Picardi Jr.J.L., Lieb S., Lee J.V., Roberts A., Hood M., Gunn R.A., Blake P.A., J Clin Microbiol 19 (1984) 296-297.

[52] Morris J.G.Jr., Wilson R., Davis B.R., Wachsmuth I.K., Riddle C.F., Wathen H.G., Pollard R.A., Blake P.A., Ann Intern Med 94 (1981) 656-658.

[53] Moss J., Vaughan M., Mol Microbiol 5 (1991) 2621-2627.

[54] Nair G.B. et al., J Clin Microbiol 44(11) 4211-4213.

[55] Nair G.B., Oku Y., Takeda Y., Ghosh A., Ghosh R.K., Chattopadhyay S., Pal S.C., Kaper J.B., Takeda T., Appl Environ Microbiol 54 (1988) 3180-3182.

[56] Nair G.B., Takeda Y., World J Microbiol Biotechnol 9 (1993) 299-400.

[57] Nambiar M.P., Oda T., Chen C., Kuwazuru Y., Wu H.C., J Cell Physiol 154 (1993) 222-228.

[58] Pal S.C., Plenum Medical Book Co. New York 3 (1992) 229-251.

[59] Peek J.A., Taylor R.K., Proc Natl Acad Sci USA 89 (1992) 6210-6214.

[60] Peterson J.W., Hejtmancik K.E., Markel D.E., Craig J.P., Kurosky A., Infect Immun 24 (1979) 774-779.

[61] Pierce N.F., J Exp Med 137 (1973) 1009-1023.

[62] Pollitzer R., W.H.O Geneva (1959).

[63] Ramamurthy T., Garg S., Sharma R., Bhattacharya S.K., Nair G.B., Shimada T., Takeda T., Karasawa T., Kurazano H., Pal A., Takeda Y., Lancet 341 (1993) 703-704.

[64] Rao B.M., Surendran P.K., Lett Appl Microbiol 51 (2010) 65-74.

[65] Rao B.M., Surendran P.K., J Food Sci Technol 50(3) (2013) 496-504.

[66] Rennels M.B., Levine M.M., Daya V., Angle P., Young C., J Infect Dis 142 (1980) 328-331.

[67] Rhine J.A., Taylor R.K., Mol Microbiol 13 (1994) 1013-1020.

[68] Rivera I.N.G., Chun J., Huq A., Sack R.B., Colwell R.R., Appl Environ Microbiol 67 (2001) 2421-2429.

[69] Said B., Scotland S.M., Rowe B., J Med Microbiol 40 (1994) 31-36. 
[70] Sakazaki R., Plenum Medical Book Co. New York 3 (1992) 37-55.

[71] Shimada T., Nair G.B., Deb B.C., Albert M.J., Sack R.B., Takeda Y., Lancet 341 (1993) 1347.

[72] Shimada T., Sakazaki R., Fujimara S., Niwano K., Mishina M., Takizawa K., Jpn J Med Sci Biol 43 (1990) 37-41.

[73] Sixma T.K., Pronk S.E., Kalk K.H., Wartna E.S., van Zanten B.A.M., Witholt B., Hol W.G.J., Nature (London) 351 (1991) 371-377.

[74] Spangler B.D., Microbiol Rev 56 (1992) 622-647.

[75] Staerk J., Ronneberger H.J., Wiegandt H., Behring Inst Mitt 55 (1974) 145-146.

[76] Svennerholm A.-M., 43rd Nobel Symposium, Stockholm 1978 S Karger Basel (1980) 171-184.

[77] Tacket C.O., Taylor R.K., Losonsky G., Lim Y., Nataro J.P., Kaper J.B., Levine M.M., Infect Immun 66 (1998) 692-695.

[78] Tamura K., Shimoda S., Prescott L.M., Jpn J Med Sci Biol 24 (1971) 125-127.

[79] Taylor R.K., Miller V.L., Furlong D.B., Mekalanos J.J., Proc Natl Acad Sci USA 84 (1987) 2833-2837.

[80] van Heyningen W.E., Seal J.R., Westview Press Boulder Colo (1983).

[81] Waldor M.K., Friedman D.I., Curr Opin Microbiol 8(4) (2005) 459-465.

[82] Waldor M.K., Mekalanos J.J., Science 272 (1996) 1910-1914.

[83] Waldor M.K., Mekalanos J.J., Lancet 343 (1994) 1366

[84] Yu J., Webb H., Hirst T.R., Mol. Microbiol 6 (1992) 1949-1958. 